\title{
125. Studies on the Wetting Effect and the Surface Tension of Solids \\ The Change in Scratch Hardness of Some Minerals and Rocks due to Wetting by Liquids
}

\author{
By Mizuho SATO
}

(Comm. by M. Masima, M.J.A., Oct. 12, 1955)

It is well known that the hardness of minerals and rocks is expressed by Mohs scale relatively in rubbing them with each other. According to experiments, ${ }^{1)}$ when the mutual attraction between atoms or molecules on a solid surface is strong, the Mohs scale of this solid is read to be high, and vice versa. In other words, the surface hardness of a hard solid is higher than that of a soft one. When the surface hardness of a solid is high, the surface tension of this solid is also to be large, because the both are increased with increasing mutual attraction between the atoms or molecules. So, if the surface tension of a solid be lowered by wetting of liquid, the surface hardness is to be decreased. In the present case, this effect is investigated taking glass, hematite, magnetite, marble, serpentine, calcite, whetstone, and steatite as

\begin{tabular}{|c|c|c|c|c|}
\hline Specimen & Hematite & Magnetite & Serpentine & Calcite \\
\hline Land of origin & $\begin{array}{l}\text { Guldsmedshyttan } \\
\text { Sweden }\end{array}$ & $\begin{array}{l}\text { Kiruna } \\
\text { Sweden }\end{array}$ & $\begin{array}{l}\text { Snarum } \\
\text { Norway }\end{array}$ & $\begin{array}{l}\text { Fengtien } \\
\text { China } \\
\end{array}$ \\
\hline Specimen & Marble & Steatite & Whetstone & Glass \\
\hline Land of origin & $\begin{array}{l}\text { Ibaraki } \\
\text { Prefecture }\end{array}$ & $\begin{array}{l}\text { Hirosima } \\
\text { Prefecture }\end{array}$ & $\begin{array}{l}\text { Hukusima } \\
\text { Prefecture }\end{array}$ & 一 \\
\hline
\end{tabular}

1) A. Eucken: Lehrbuch der chemischen Physik, Leipzig, 987 (1930). The relation between the atomic or molecular distance $d$ and Mohs hardness $H$ in some crystal lattices of the same kind and the equal valency is given as follows:

\begin{tabular}{|c|c|c|c|c|c|c|c|c|}
\hline \multirow{2}{*}{$\begin{array}{l}\text { Element } \\
d \text { and } H\end{array}$} & \multicolumn{2}{|c|}{$\mathrm{Mg}$} & \multicolumn{2}{|c|}{$\mathbf{C a}$} & \multicolumn{2}{|c|}{$\mathrm{Sr}$} & \multicolumn{2}{|c|}{$\mathrm{Ba}$} \\
\hline & $d$ & $H$ & $d$ & $H$ & $d$ & $H$ & $d$ & $H$ \\
\hline $\begin{array}{l}\mathrm{O} \\
\mathrm{S} \\
\mathrm{Se} \\
\mathrm{Te}\end{array}$ & $\begin{array}{l}2.10 \\
2.59 \\
2.74 \\
-\end{array}$ & $\begin{array}{l}6.5 \\
4.5 \sim 5 \\
3.5 \\
-\end{array}$ & $\begin{array}{l}2.80 \\
2.84 \\
2.96 \\
3.17\end{array}$ & $\begin{array}{l}4.5 \\
4.0 \\
3.2 \\
2.9\end{array}$ & $\begin{array}{l}2.57 \\
3.00 \\
3.12 \\
3.32\end{array}$ & $\begin{array}{l}3.5 \\
\text { ca. } 3.0 \\
\text { ca. } 2.9 \\
\text { ca. } 2.8\end{array}$ & $\begin{array}{l}2.77 \\
3.18 \\
3.31 \\
3.49\end{array}$ & $\begin{aligned} & 3.3 \\
& 3 \\
& \text { ca. } 2.7 \\
& \text { ca. } 2.6\end{aligned}$ \\
\hline
\end{tabular}

In the same literature the relation between the hardness $H$ and the distance $d$ is also given:

\begin{tabular}{|c|c|c|c|c|c|c|c|}
\hline Lattice & \multicolumn{2}{|c|}{ Ionic lattice } & \multicolumn{5}{|c|}{ Atomic lattice } \\
\hline Valency & 1. & 2 & 1 & & 2 & & 3 \\
\hline$d \fallingdotseq 2.35$ & $3.2(\mathrm{NaF})$ & $4.5(\mathrm{CaO})$ & $2.5(\mathrm{CuCl})$ & 4 & $(\mathrm{ZnS})$ & 5 & $(\mathrm{GaP})$ \\
\hline$d \fallingdotseq 2.80$ & $2.5(\mathrm{NaCl})$ & $3.3(\mathrm{BaO})$ & $1.5(\mathrm{AgJ})$ & 2.8 & (CdTe) & 3.8 & (InSb) \\
\hline
\end{tabular}


the specimens. ${ }^{2)}$ The lands of origin of these materials are shown in the above table.

In order to find the change in the surface hardness, a scratch test has been tried in dry and wet states, measuring the change in width of the scratch marked by means of Martens hardness tester under the load of $20 \mathrm{~g}$. The width of scratch has been measured on the comparator with a microscope whose magnification amounts to 150 times. Experiment has been performed at a room temperature of $28 \sim 30^{\circ} \mathrm{C}$, repeating the tests in each of dry and wet states at least 10 times. Data obtained are given in Figs. $1 \sim 3$.

In Fig. 1 the change in scratch hardness of the specimens due to wetting by distilled water is shown, in which the Vickers

Relative decrease in scratch hardness $\longrightarrow$

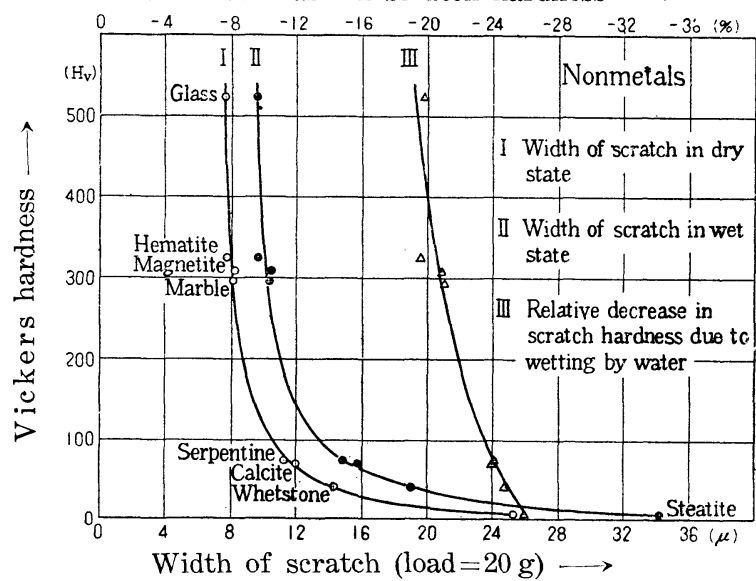

Fig. 1. Change in scratch hardness of nonmetals due to wetting by distilled water hardness $H_{V}$ and the width $s$ of the scratches are taken along the ordinate and the abscissa respectively.

The curve I gives a $H_{V} s$-relation in dry state, while the curve II a similar relation in wet state. As seen from these curves, the width of scratch is increased by the wetting, showing that the scratch hardness is decreased in the presence of water.

When the scratch hardness ${ }^{3)}$ is defined by the reciprocal of the width $s$ of scratch, then the relative change $\sigma$ in the scratch hardness is given by $-\Delta s / s^{\prime}$, where $s^{\prime}$ is the width of the scratch in wet state; $\Delta s=s^{\prime}-s$ is positive in the present case. The values of $\sigma$ for glass, hematite, magnetite, marble, serpentine, calcite, whetstone, and steatite are evaluated to be $-19.8,-19.6,-20.9,-21.1$, $-24.1,-24.0,-24.7$, and -25.9 per cent respectively. These values are plotted as shown by the curve III in Fig. 1 . As seen from this curve, the decrease in the scratch hardness of hard minerals is

2) The specimens of hematite, magnetite, and serpentine were sent by Professor Carl Benedicks of Stockholm. On this occasion the author wishes to express his cordial thanks to the Professor for his kind offer of his valuable specimens.

3) Denoting the scratch hardness and the width of scratch with $H_{s}$ and $s$ respectively, one defines $H_{s}=1 / s$. Similarly, it holds $H_{s}{ }^{\prime}=1 / s^{\prime}$ in wet state. So, the relative change $\sigma$ in $H_{s}$ due to the wetting is given by the formula:

$$
\sigma=\frac{\Delta H_{s}}{H_{s}}=\left(\begin{array}{cc}
1 & 1 \\
s^{\prime} & -
\end{array}\right) \quad \begin{aligned}
& 1 \\
& s
\end{aligned}=-\begin{gathered}
s^{\prime}-s \\
s^{\prime}
\end{gathered}=-\frac{\Delta s}{s^{\prime}} .
$$


relatively small, while it is increased for soft one, showing that the curve III is at first drawn steeply and then by an easy slope. As described already, the surface tension of a hard mineral is stronger than that of a soft one, the relative decrease in the scratch hardness of the former should be smaller than that of the latter. It seems that this idea is verified by the experimental data plotted in the curve III. In Photo an example of the scratches marked on the specimen of hematite is shown.

Next, it is required to investigate whether the scratch hardness of a given specimen is linearly be decreased with increasing surface tension of wetting liquids or not. Fig. 2 shows an example of the observation taking the specimen of hematite wetted by methanol, glycerine, and distilled water. The scratch hardness under the load of $20 \mathrm{~g}$ is lowered with increasing surface tension of the wetting liquids as shown by a descending straight line in this figure where the scratch hardness $H_{s}$ in $\mathrm{mm}^{-1}$ and the surface tension in $\mathrm{dyn} / \mathrm{cm}$ of the wetting liquids are taken along the ordinate and the abscissa respectively. This datum means that the smaller the interfacial tension is, the lower the surface hardness.

Fig. 3 gives an example of the observation concerning the relation between the wetting effect

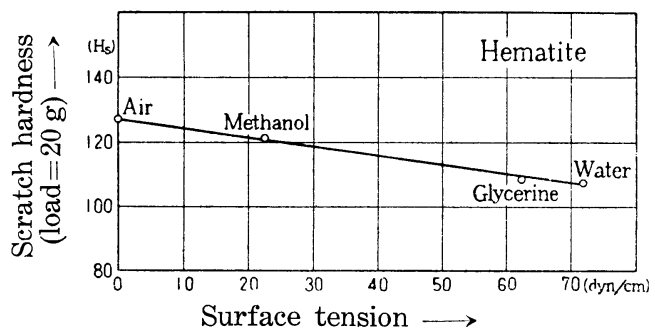

Fig. 2. Change in scratch hardness of hematite due to wetting by methanol, glycerine, and distilled water

Scratches on hematite specimen $(\times 88)$

A : Dry in air

W: Wet in water

Relative decrease in scratch hardness $\longrightarrow$

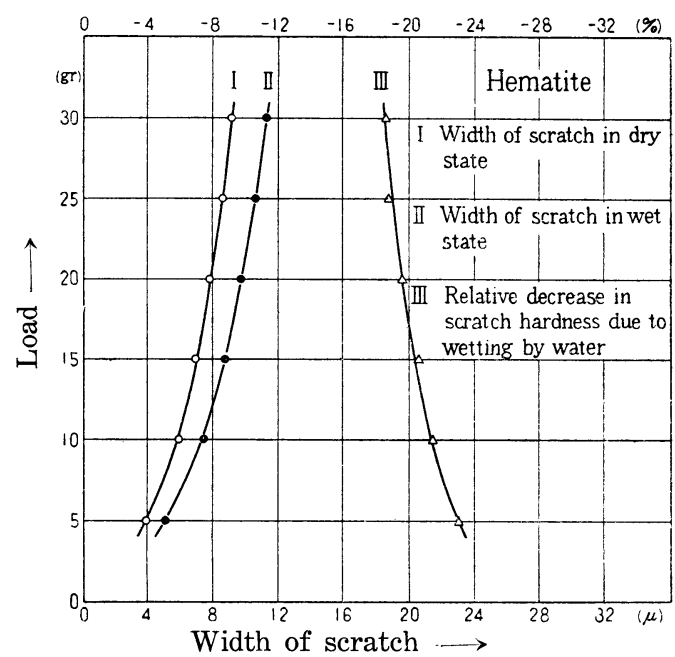

Fig. 3. Relation between the load and the wetting effect on hematite due to wetting by distilled water 
and the load taking the specimen of hematite wetted by distilled water. In this figure the load in gram and the width of the scratch in micron are taken along the ordinate and the abscissa respectively. As seen from this figure, the relative decrease in scratch hardness due to the wetting is pronounced with decreasing load. The more superficial the scratch is, the more the influence becomes effective, as seen from the curve III in the same figure.

According to Benedicks, ${ }^{4)}$ the bending strength of a quenched carbon steel, glass, marble, gypsum, sugar II, and sugar I is decreased by the wetting. He has given a remarkable relation between the relative decrease in the bending strength due to wetting and Mohs hardness. In this relation it is seen that the relative decrease in the strength for a hard material is smaller than that for a soft one forming a continuous curve which starts with a nearly rectilinear portion and then slightly bends off horizontally ${ }^{5)}$ in a good resemblance to the curve III in Fig. 1. It is interesting to see that the author's result of observation in the scratch hardness harmonizes with that observed by Benedicks in his test of the bending strength.

4) C. Benedicks and R. Härdén: Ark. Fys., Stockholm, 3, 407 (1951).

5) In Fig. 9 on page 416 of the above literature, Professor Benedicks has shown the following data.

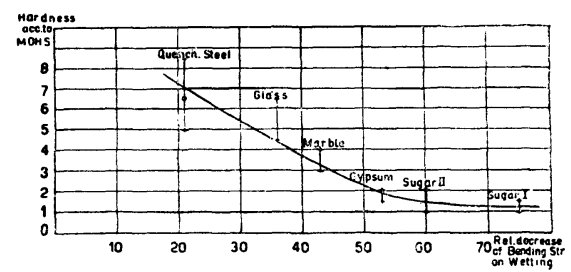

Relation between the relative decrease in bending strength and the $\mathrm{Mohs}$ hardness (Professor Benedi $\mathrm{cks}$ )

It is to be noted that the above curve and the author's curve III in Fig. 1 resemble each other in shape. 